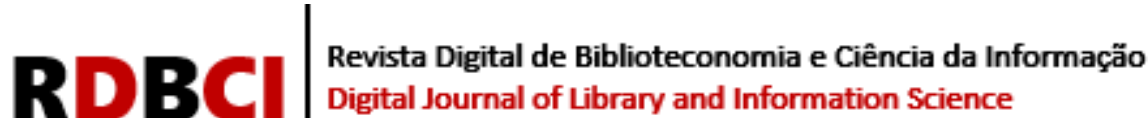

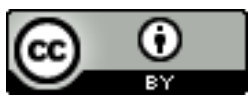

\section{Contribuições da Biblioteconomia e Ciência da Informação para a gestão de bibliotecas universitárias}

\author{
Fernanda Vasconcelos Amaral ${ }^{1}$ (iD) https://orcid.org/0000-0001-6197-9548 \\ Elisa Cristina Delfini Corrêa ${ }^{2}$ (iD https://orcid.org/0000-0001-7738-1727 \\ ${ }^{1}$ Universidade Federal de Lavras, Lavras, MG, Brasil. / e-mail: fernandav.br@gmail.com \\ ${ }^{2}$ Universidade do Estado de Santa Catarina, Florianópolis, SC, Brasil. / e-mail: elisacorrea61@ @mail.com
}

\begin{abstract}
RESUMO
A Biblioteconomia e a Ciência da Informação são dois campos que possuem intrínseca relação entre si, principalmente no Brasil. Contudo, apesar das convergências, essas áreas surgiram em períodos históricos diferentes e com objetivos de atender demandas bem específicas. Atualmente, percebe-se que a Biblioteconomia está mais centrada em questões relacionadas com responsabilidade social e democratização da educação, enquanto a Ciência da Informação foca seus esforços em pesquisas relacionadas à compreensão da informação enquanto fenômeno em diferentes contextos. Dentre estes, interessa a este artigo, a informação estratégica e profissional, dentro de organizações. Entre esses dois enfoques, está a biblioteca universitária, que ocupa um papel de destaque tanto na área da educação como na de planejamento estratégico de um país. Por isso, o propósito deste artigo é analisar as contribuições dos dois campos para a gestão de bibliotecas universitárias na atualidade. Por meio da revisão de literatura, conclui-se que as duas áreas fornecem insumos complementares que propiciam aos gestores dessas unidades criarem um ambiente e serviços que atendam de forma mais satisfatória seus usuários. A Biblioteconomia traz contribuições tanto na parte técnica quanto humanística para as bibliotecas universitárias, enquanto a Ciência da Informação contribui com questões relacionadas a instabilidade da sociedade atual, que demanda constantes redefinições dos serviços prestados.
\end{abstract}

PALAVRAS-CHAVE

Biblioteconomia. Ciência da Informação. Bibliotecas universitárias. Gestão de bibliotecas.

\section{Library and Information Science contributions to university libraries management}

\begin{abstract}
Librarianship and Information Science are two fields that have intrinsic relation between each other, mainly in Brazil. However, in spite of the convergences, these areas arose in different historical periods and with objectives to meet very specific demands. Currently, it is noticed that Librarianship is more focused on issues related to social responsibility and democratization of education, while Information Science focuses its efforts on research in order to understand information as a phenomenon in different contexts. Among these, this article is interesting, in the strategic and professional information, usually within organizations. Between these two approaches is the university library, which occupies a prominent role in the area of education as well as strategic planning of a country. Therefore, the purpose of this article is to analyze the contributions of the two fields for the management of university libraries today. Through the literature review, it is concluded that the two areas provide complementary inputs that allow the mana\$gers of these units to create an environment and services that meet the needs of their users in a more satisfactorily way. Librarianship brings both technical and humanistic contributions
\end{abstract}




\section{RDBCI}

to university libraries, while Information Science contributes to issues related to the instability of today's society, which demands constant redefinition of the services provided.

\section{KEYWORDS}

Librarianship. Information Sciences. Academic libraries. Libraries management.

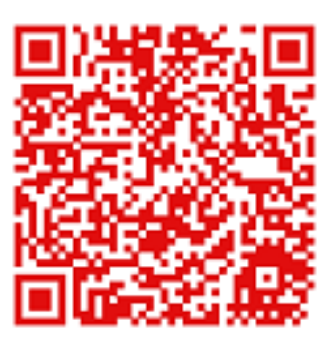

JITA: DD. Academic libraries. 


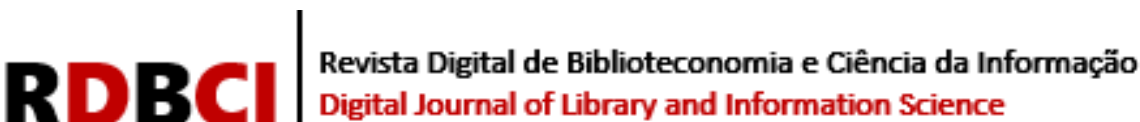

\section{INTRODUÇÃO}

Os campos de pesquisa da Biblioteconomia e da Ciência da Informação (CI) possuem uma relação tão intrínseca entre si que no Brasil chegam a si confundir. Contudo, enquanto a primeira é uma área do conhecimento milenar e já consolidada, a segunda se encaixa no panorama das ciências pós-modernas e ainda luta para adquirir maturidade científica. Permeando esses campos, há uma polaridade entre duas necessidades informacionais bastante distintas uma da outra: as demandas públicas e de democratização da educação; e as demandas privadas e de competitividade econômica e comercial. Enquanto a primeira busca o livre acesso à informação e é mais voltada para a questão social, a segunda restringe o acesso à informação e é mais voltada para aspectos tecnológicos e mercadológicos.

Entre as interseções e particularidades desses dois campos, estão inseridas as bibliotecas universitárias, que se constituem em um fértil campo de pesquisa. As universidades, principalmente as públicas, possuem um duplo papel tanto de formarem bons profissionais para o mercado e pesquisadores para a área acadêmica quanto de impactar positivamente a vida em sociedade. Ou seja, mais do que formar mão-de-obra, as universidades deveriam preocupar-se também em formar cidadãos com consciência de sua responsabilidade social e capazes de solucionar problemas e desafios da comunidade onde estão inseridos. As bibliotecas dessas instituições, por sua vez, têm o papel de auxiliar no alcance desses objetivos.

Dessa forma, o presente artigo indica as relações entre as áreas de Biblioteconomia e Ciência da Informação e identifica como uma síntese das duas áreas pode contribuir para o desenvolvimento dos serviços prestados pelas bibliotecas universitárias (BU). O objetivo é demonstrar que os conflitos entre esses campos devem ser superados para haver uma cooperação e análise holística que permita dinamizar e modernizar o atendimento dos usuários nas BUs.

A metodologia adotada é a revisão de literatura em livros e artigos acadêmicos. $\mathrm{O}$ foco deste levantamento bibliográfico é caracterizar as áreas de Biblioteconomia e Ciência da Informação e estabelecer as convergências e divergências existentes. Em seguida, serão analisados como os paradigmas, as técnicas e objetos de estudo desses campos podem ser empregados na gestão de bibliotecas universitárias para que os objetivos institucionais dessas unidades de informação sejam alcançados satisfatoriamente.

Na primeira parte da revisão, há uma apresentação das origens da Biblioteconomia, seu desenvolvimento através do tempo e o papel das bibliotecas na sociedade contemporânea. A segunda parte versa sobre o surgimento da Ciência da Informação, sua interdisciplinaridade e crise identitária no contexto pós-moderno. Por fim, será apresentado como os gestores de bibliotecas universitárias podem se apropriar dos preceitos dessas duas áreas para desenvolver atividades que tornem essas unidades de informações relevantes para a comunidade atendida.

\section{BIBLIOTECONOMIA: FUNÇÃO SOCIAL E RELEVÂNCIA NA ATUALIDADE}

Segundo Fonseca (2007, p. 1), Biblioteconomia é "o conjunto de regras de acordo com as quais os livros são organizados em espaços apropriados: estantes, salas, edifícios”. Essa definição advém da etimologia do termo biblioteconomia, que é composto pelos elementos gregos biblion (livro), théke (caixa) e nomos (regras). Atualmente, contudo, dada a evolução das bibliotecas e outras unidades de informação, a área sofreu uma expansão e abrange a organização e disseminação da informação nos mais variados ambientes e formatos.

O desenvolvimento da Biblioteconomia está intimamente relacionado com o papel atribuído às bibliotecas durante o passar do tempo. Inicialmente, esses espaços serviam apenas 


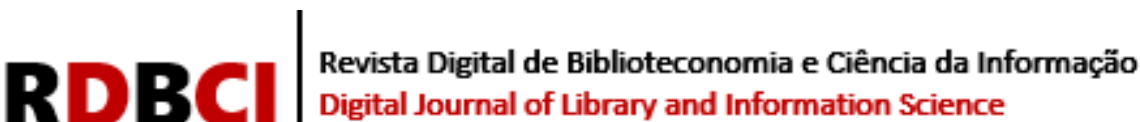

para armazenamento (depósito) de materiais para a preservação de seus conteúdos e suporte físico, sem que houvesse grandes preocupações com o acesso e circulação dos documentos. Até o Renascimento, as bibliotecas eram, normalmente, propriedades de instituições religiosas e não eram acessíveis à população em geral. As bibliotecas europeias da Idade Média, por exemplo, estavam alojadas no interior de conventos e mosteiros, lugares inacessíveis aos laicos, e os livros eram até mesmo acorrentados às estantes ou mesas para leitura (MARTINS, 1998). A própria noção de leitor também é moderna, pois na Antiguidade e na Idade Média a imensa maioria da população, mesmo a nobreza, era iletrada, sendo que até mesmo alguns padres eram analfabetos. No século XIII, quando são fundadas as primeiras universidades, surgem também as bibliotecas universitárias, ainda como um prolongamento das instituições eclesiásticas, pois muitas se originaram das ordens dos franciscanos e dominicanos (MARTINS, 1998). Lentamente, a administração das bibliotecas é laicizada e, com isso, o acesso aos livros tornase mais amplo e democrático, embora o elitismo do acesso às bibliotecas ainda perdure por mais um longo período até que se torne aberta a todos os segmentos da população. No século $\mathrm{XV}$, Gutenberg inventa a imprensa e ocorre a primeira explosão bibliográfica, rompendo com o monopólio da Igreja na salvaguarda dos livros. Surge então a necessidade não apenas de armazenar materiais como também inventariar e organizar a produção bibliográfica da humanidade e torná-la acessível para utilização. Com o Iluminismo, nos séculos XVII e XVIII, as bibliotecas ganham relevância devido seu papel de guardião da memória da humanidade e de agente democratizador do conhecimento. Já no século XIX, com a consolidação das ciências modernas, as bibliotecas passam a auxiliar no desenvolvimento científico da sociedade. Mais recentemente, devido à automatização/mecanização das atividades, à segunda explosão bibliográfica ao fim da Segunda Guerra Mundial e ao desenvolvimento das tecnologias de informação e comunicação, as bibliotecas novamente necessitam se adaptar e desenvolver novos serviços e atividades que atendem às demandas dos usuários inseridos na assim chamada sociedade da informação. A partir do século XX, nos países desenvolvidos, as bibliotecas, principalmente as públicas, assumem uma função estratégica de fomentar a educação e cultura perante a população, em movimento liderado nos Estados Unidos pela Escola de Chicago. Nos países em desenvolvimento, como o Brasil, contudo, ainda há vários empecilhos na atuação dessas instituições devido à falta de verbas e descaso político.

Segundo Ortega (2004),

\begin{abstract}
A Biblioteconomia tem origem efetiva na atividade de preservação das unidades do conhecimento registrado, alterando-se com o tempo por meio da democratização do acesso à educação e à cultura em atividade de gestão de serviços de biblioteca, porém sem constituir área cientificamente fundamentada no seu todo. É marcada pela intensa disseminação de seus equipamentos físicos, as bibliotecas, muitas das quais estabeleceram redes cooperativas de catalogação, cujos laços são essencialmente produtivos e formais, mas não estabelecidos com base na informação e seu contexto de produção e uso.
\end{abstract}

Desta forma, embora exista o termo em inglês Library Science, para muitos teóricos a Biblioteconomia é considerada uma disciplina e não uma ciência propriamente dita (LE COADIC, 2004), pois seus preceitos estão voltados para a aplicação prática de técnicas e métodos que propiciem a organização, recuperação e disseminação da informação, sem que haja um imperativo científico obrigatoriamente permeando a área, constituindo-se como um campo do conhecimento com raízes muito pragmáticas.

Enquanto prática profissional, a Biblioteconomia está associada a funções de desenvolvimento de coleção; classificação, catalogação e recuperação de informações; atendimento de demandas informacionais (serviços de referência); e gerenciamento de unidades de informação. Embora essas atividades estejam enfrentando drásticas mudanças devido às 


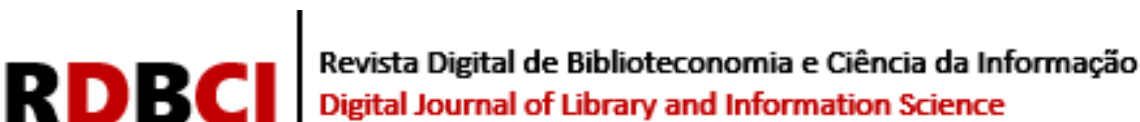

inovações tecnológicas, "praticamente todas essas funções permanecerão necessárias e deverão ser realizadas de uma forma ou de outra, seja por intermediários humanos, seja por sistemas automatizados" (DIAS, 2000, p. 71). Por isso, o bibliotecário deve ficar atento para o movimento de transposição de suas atividades dos espaços físicos das bibliotecas para ambientes virtuais, pois embora a essência do trabalho seja a mesma, as práticas e técnicas envolvidas estão sofrendo modificações.

É possível observar que o foco das pesquisas e a abordagem para desenvolver as teorias na área de Biblioteconomia foram alterados ao longo do tempo, a medida que o papel das bibliotecas na sociedade foi se transformando. Criticada por preocupar-se apenas com seus acervos e suas técnicas, as bibliotecas começam a se voltar para seus usuários e a comunidade onde está inserida. Dessa forma, o estudo das problemáticas da Biblioteconomia é ampliado e aprofundado.

Segundo Araújo (2014a, p. 28), o espanhol Lasso de la Vega (1952) argumenta que

[...] inicialmente, as bibliotecas eram instituições voltadas unicamente para a conservação dos livros e que, depois, passaram a se constituir instituições pedagógicas ativas, verdadeiras universidades populares. Na evolução do conceito de biblioteca, segundo este autor, tal instituição saiu de um papel de depósito de livros postos ao alcance de alguns privilegiados para tornar-se a 'mais democrática' das instituições. As bibliotecas teriam conseguido isso abandonando a posição passiva de esperar pelos usuários e assumindo a tarefa de buscar o livro adequado para cada leitor. Além disso, vincularam-se a uma perspectiva de eficácia na medida em que buscaram fazer os livros renderem a cada cidadão o máximo fruto, de forma mais eficaz e no menor tempo possível.

Nos países do Terceiro Mundo, após o processo de redemocratização que se seguiu ao fim das ditaduras militares instauradas durante a Guerra Fria, há uma preocupação em inserir as populações marginalizadas ou excluídas dentro das políticas de acesso à biblioteca (ARAÚJO, 2014a). A Biblioteconomia assume então um caráter de agente democratizador do acesso a informação, se afasta das origens elitistas da época do surgimento das primeiras bibliotecas e começa a promover mais ações culturais para se aproximar de seu público e promover a utilização de seu acervo.

Posteriormente, percebe-se que, apesar das várias mudanças, a Biblioteconomia ainda trata o usuário como um sujeito passivo, que apenas recebe estímulos exteriores, como na ideia da tábula rasa do fílósofo John Locke, que coloca o indivíduo como um receptáculo vazio a ser preenchido. Mais uma vez criticada, a Biblioteconomia passa a posicionar o usuário como um agente ativo no processo de acesso à informação e começa a realizar estudos de usuários e de comunidades, necessidades e usos da informação e hábitos de leitura. Nesses estudos, a abordagem construtivista ganha destaque para analisar o processo de apropriação da informação e construção do conhecimento.

$\mathrm{Na}$ área de representação da informação, vários sistemas são desenvolvidos para descrever e organizar a informação. Na catalogação, surgem instrumentos como o American Cataloguing Rules (AACR), International Standard Bibliographic Description (ISBD), padrão Dublin Core e o Functional Requirements for Bibliographic Records (FRBR). Na classificação, pode-se citar a Classificação Decimal de Dewey (CDD), a Classificação Decimal Universal (CDU), a classificação da Library of Congress e os sistemas de Charles Ami Cutter e de Raganathan (PMEST e classificação facetada de Dois Pontos). As linguagens de indexação, por sua vez, tornam-se fundamentais para fazer a ponte entre a coleção e o usuário, principalmente após o início da automatização das bibliotecas. Percebe-se com o processo de criação desses instrumentos que "a tendência universalizante, aos poucos, foi cedendo lugar à questão do singular" (ARAÚJO, 2014a, p. 73). Ou seja, reconhece-se que tanto a descrição quanto a 


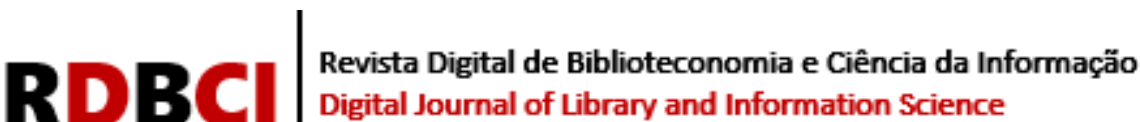

organização das coleções das bibliotecas devem ser realizadas de acordo com o público atendido e com um posicionamento crítico. Por exemplo, em uma biblioteca escolar, um sistema de organização baseado em cores pode ser muito mais prático e eficaz do que o simples uso de números de classificação. Ao invés de esperar que o usuário se adapte aos procedimentos e normas da biblioteca, a Biblioteconomia começa a moldar suas técnicas e ações de acordo com os inputs dos usuários. A organização e recuperação da informação são bastante afetadas e assuntos como folksonomia e interação homem-sistemas ganham destaque.

De acordo com Araújo (2014a), no contexto contemporâneo, a Biblioteconomia voltase para modelos de interação e mediação de forma dialética com o público atendido e procura superar os modelos que promoviam apenas ações unilaterais das instituições junto aos usuários. Há uma ênfase também na necessidade de integrar as ações, acervos ou serviços das unidades de informação em modelos sistêmicos e holísticos ao invés de fragmentá-los e tratá-los isoladamente. Dessa forma, o profissional bibliotecário assume a importante função de ser um mediador que, além de ser uma ponte entre a informação e o indivíduo, é responsável também por auxiliar no desenvolvimento da competência informacional do usuário para que este possua a capacidade de buscar informação com autonomia, independência e consciência crítica, seja no ambiente tradicional das bibliotecas físicas como também em bibliotecas eletrônicas e outras fontes digitais.

A Biblioteconomia, portanto, permanece como um campo em constante expansão e adaptação, com um papel social cada vez mais aflorado para auxiliar os indivíduos a compreenderam a realidade onde estão inseridos e a promover as mudanças necessárias. A função técnica da área continua importante, mas a função educadora e social da biblioteca é elevada e cada vez mais necessária para contribuir no desenvolvimento dos indivíduos tanto em sua capacidade pessoal e profissional como também em uma dimensão coletiva enquanto cidadão capaz de alterar a realidade onde vive de forma crítica e atuante.

\section{CIÊNCIA DA INFORMAÇÃO: FUNÇÃO ESTRATÉGICA E PÓS-MODERNIDADE}

A Ciência da Informação surgiu oficialmente na década de 1940, no bojo da explosão informacional que ocorreu após a Segunda Guerra Mundial. Naquele período, a polarização entre as duas superpotências da época, Estados Unidos e União Soviética, provocou uma corrida armamentista e uma disputa política que fez florescer o desenvolvimento tecnológico e científico. A informação tornou-se então um insumo para a continuação de pesquisas e também um fator de poder, na medida que esses dois países buscavam suprir as regiões sob sua influência com informações científicas e estratégicas. Incapazes de lidar com o enorme volume informacional gerado diariamente, torna-se latente a criação de métodos mais eficazes para organizar, recuperar e disseminar a informação presente nos mais variados formatos e demandadas por usuários com necessidades cada vez mais específicas. Após o fim da Guerra Fria, a demanda por informação continua, mas tem seu eixo expandido dos governos para as organizações privadas, que também buscam por maior competitividade por meio da inovação e aperfeiçoamento contínuo.

Fortemente interdisciplinar, a CI tem em suas origens evidentes vínculos com a Biblioteconomia e a Documentação, tendo sido marcada pelas ideias visionárias de Paul Otlet (ARAÚJO, 2011), assim como com a Ciência da Computação (especialmente no que se relaciona com a recuperação automática da informação), a Psicologia Cognitiva, a Comunicação, entre outros campos afins. É importante observar que a origem da CI em cada país possui variações, sendo que em alguns há uma conexão mais estreita com uma das áreas

RDBCl: Rev. Dig. Bibliotec e Ci. Info. / RDBCl: Dig. J. of Lib. and Info. Sci. | Campinas, SP | v.18| e020008 | 2020 


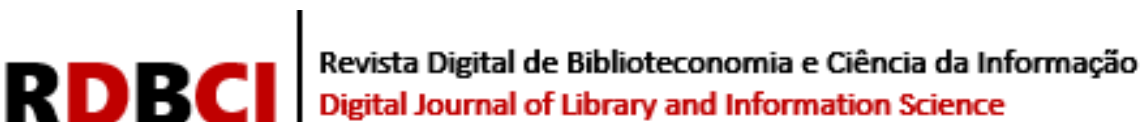

citadas acima. Nos Estados Unidos, por exemplo, a CI surge atrelada aos sistemas tecnológicos de recuperação da informação e também como uma demanda das bibliotecas especializadas, que já não conseguiam atender satisfatoriamente seus usuários apenas com o conhecimento gerado na área de Biblioteconomia (DIAS, 2000). Na França, por sua vez, a área está institucionalizada nos departamentos de Ciências da Comunicação (ARAÚJO, 2014a).

No Brasil, a CI foi introduzida com o mestrado criado pelo Instituto Brasileiro de Bibliografia e Documentação (IBBD), precursor do Instituto Brasileiro de Informação em Ciência e Tecnologia (IBICT), em 1970 e seu surgimento esteve ligado às necessidades do governo, que possuía o objetivo de vincular o desenvolvimento da ciência ao setor produtivo (MARTELETO, 2009). Dessa forma, a pesquisa em CI foi estruturada na informação para o Estado e voltada para as políticas desenvolvimentistas implementadas na época pelo governo. Institucionalmente, a Ciência da Informação no Brasil está diretamente ligada aos departamentos de Biblioteconomia, que oferecem cursos de pós-graduação na área. Entretanto, cada vez mais é possível encontrar profissionais de outras áreas (predominantemente engenheiros e cientistas da computação) ocupando as vagas de professores nesses departamentos.

Uma das grandes dificuldades na institucionalização da Ciência da Informação foi e continua sendo seu caráter interdisciplinar, pois essa característica dificulta a evolução da área ao fracionar em diversos campos a análise de seu objeto de estudo, a informação. Desse modo, a CI depende da síntese das teorias apropriadas das outras ciências para elaborar sua própria epistemologia, pois não é possível apenas incorporar os conceitos vindos das outras áreas, é necessário interpretá-los e adequá-los para o campo da Ciência da Informação. A interdisciplinaridade, portanto, constitui-se numa fragilidade e numa força ao mesmo tempo: é uma deficiência na medida em que não possui uma base conceitual-teórica própria e bem estruturada (utilizando teorias alheias como um apoio no desenvolvimento de suas pesquisas), mas é um ponto forte ao propiciar à CI realizar estudos mais holísticos que outros campos do conhecimento.

Essa grande interdisciplinaridade é também responsável pela crise de identidade da área, que oscila entre querer ser uma "ciência dura", com preceitos bem demarcados, e ser uma ciência social, que respeita as particularidades do indivíduo e das comunidades estudadas. Ao analisar a trajetória das pesquisas, percebe-se que inicialmente, a CI surge com uma abordagem positivista/funcionalista e procura atingir um conhecimento mais exato, com modelos matemáticos (teoria da informação), físicos (entropia) ou biológicos (teoria epidemiológica). Dessa forma, "se em termos institucionais ou terminológicos parece indiscutível a natureza social da ciência da informação, em termos propriamente teórico epistemológicos essa inserção não é exatamente óbvia" (ARAÚJO, 2003, p. 21).

Esta perspectiva só é alterada quando, posteriormente, o enfoque das pesquisas é redirecionado para os usuários, necessitando a partir de então buscar a contribuição das ciências humanas e sociais. Mas mesmo assim, os primeiros estudos da CI como ciência social tiveram um enfoque marcadamente estatístico e quantitativo, talvez como uma tentativa de trazer mais legitimidade e respeitabilidade acadêmica à área. "Portanto, a ciência da informação não "nasce" ainda como uma ciência social. Muito ligada inicialmente à computação (...) e à recuperação automática da informação, ela vai, apenas nos anos 70, promover sua inscrição efetiva nas ciências sociais" (ARAÚJO, 2003, p. 22). Posteriormente, a CI assume seu caráter social e passa a desenvolver estudos que consideram a informação de uma forma mais contextualizada, reconhecendo que o valor informacional não existe a priori, mas é dependente de um dado contexto.

O novo direcionamento da Ciência da Informação não é um caso isolado na comunidade científica e acadêmica. Na realidade, é um sintoma do início da crise das ciências 


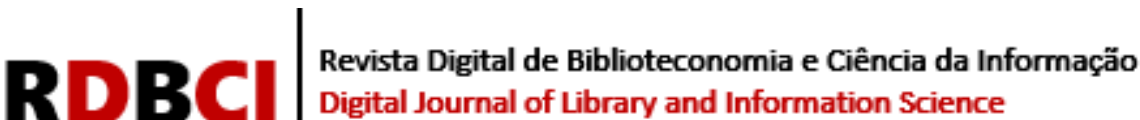

modernas, que passam a ser duramente criticadas, e faz emergir uma nova forma de fazer ciência, que pode ser caracterizada como um

\begin{abstract}
movimento de superação da crise do paradigma científico dominante desde o século XVII, pela superação do modelo de racionalidade cartesiana, de separação do sujeito e do objeto, a busca da ordem, a separabilidade dos elementos constituintes da realidade, movimento esse motivado pelas crises geradas com a evolução e a aplicação do conhecimento científico, tais como as guerras, os regimes totalitários, a poluição e os desastres ecológicos, a exclusão do acesso ao conhecimento, reforço das desigualdades socioeconômicas, a sofisticação dos instrumentos de dominação. (SANTOS, 1996 apud ARAÚJO, 2003, p. 26).
\end{abstract}

As ciências pós-modernas, portanto, surgem da exigência de uma nova reconfiguração para a ciência no mundo contemporâneo, onde não será necessário explicar todas as nuances dos objetos estudados e o campo de estudo é voltado para a resolução de problemas causados pelas ciências clássicas e pelas tecnologias criadas anteriormente. Além disso, é reconhecida a impossibilidade da objetividade, pois o pesquisador é incapaz de desligar-se de seu contexto político, econômico, social e ideólogo. Sem mencionar que as pesquisas são financiadas pelo governo e pela iniciativa privada, que, naturalmente, possuem suas próprias motivações nos resultados das pesquisas por eles patrocinadas.

A exigência de uma nova ciência decorre do fracasso dos ideais iluministas, que acreditavam que através da razão seria possível construir um mundo mais justo e em constante progresso (CARDOSO, 1996). Contudo, a própria noção de progresso passa a ser questionada e várias invenções científicas provocam grandes tragédias, como a bomba atômica e a destruição do meio ambiente de forma irreparável. Até mesmo as ciências sociais, ao apropriarse das ideias evolutivas de Darwin, fornecem embasamento para justificar atos como a colonização da África, onde os "povos primitivos" finalmente alcançariam a civilização por intermédio das nações "avançadas", num claro desrespeito a história e tradição dos países "invadidos".

O conceito de pós-modernidade, contudo, é polêmico. Muitos autores acreditam que o que ocorre atualmente é um acirramento das características modernas e não um rompimento com a ordem anterior. A sociedade contemporânea estaria no meio de uma crise de valores, mas esta crise é que levaria à posterior estabilidade. Outros autores, contudo, acreditam que não há mais volta e que a sociedade mudou de tal forma que romperá definitivamente os preceitos já estabelecidos pelo homem.

Independente da discussão sobre se houve ou não um rompimento com ordem moderna, algumas características podem ser depreendidas da sociedade contemporânea em que vivemos: a ruptura do espaço-tempo, os avanços nas tecnologias de comunicação e o exacerbamento dos efeitos da globalização (GIDDENS, 1991 apud CARDOSO, 1996). A principal consequência destas mudanças é a possibilidade de comunicação e convivência entre os indivíduos de diferentes partes do mundo tanto socialmente quanto economicamente, facilitando o intercâmbio de conhecimento entre os povos. Por isso que estudos centrados em sistemas fechados, como ocorriam na área de Biblioteconomia e Ciência da Informação inicialmente, não fazem mais sentido, pois o indivíduo atualmente está em permanente conexão com diversos sistemas informacionais todo o tempo e, muitas vezes, simultaneamente.

$\mathrm{Na}$ área científica, a grande mudança é o reconhecimento da subjetividade nas pesquisas; da instabilidade do conhecimento, que pode ser alterado e substituído por novas descobertas a qualquer momento; da impossibilidade do saber universal e absoluto, pois os objetos de estudo são dependentes de seu contexto (teoria da relatividade); e, talvez a mudança mais significativa, a interdisciplinaridade, pois uma única ciência não consegue sozinha ser 


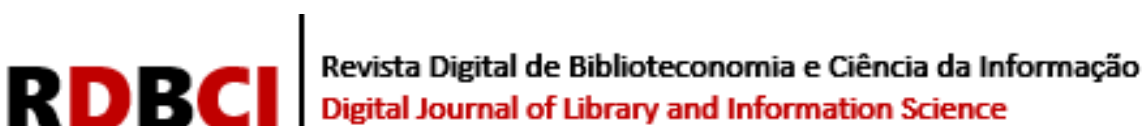

responsável por solucionar os complexos problemas estudados pela área científica contemporânea (ARAÚJO, 2003). No contexto da pós-modernidade, mesmo áreas consideradas como ciências duras tiveram que alterar seus paradigmas diante de certos problemas, como a física, por exemplo, que lida hoje com a física clássica, a física quântica e a teoria das cordas, para citar alguns conceitos. Dessa forma, o constante questionamento da objetividade na ciência, ou a falta dela, visa indagar sobre os limites do método científico e demonstrar que não há verdades absolutas, pois tudo depende do contexto e do recorte realizado durante as pesquisas. Essa abertura é o que permite que a ciência continue o seu desenvolvimento e promova inovações disruptivas. Por isso, a CI nesse cenário deixa de buscar o respaldo de ser considerada uma ciência dura e abraça a ideia de ser uma ciência pós-moderna, com todas as suas possibilidades.

Dada as alterações que ocorreram nos estudos dentro da área de CI, é possível demarcar três paradigmas principais a embasarem as pesquisas desse campo do conhecimento:

Quadro 1. Paradigmas da Ciência da Informação

\begin{tabular}{|c|c|c|c|}
\hline & $\begin{array}{l}\text { PARADIGMA } \\
\text { FÍSICO }\end{array}$ & $\begin{array}{c}\text { PARADIGMA } \\
\text { COGNITIVO }\end{array}$ & PARADIGMA SOCIAL \\
\hline PERÍODO & Década de 1940 & Década de 1970 & Década de 1990 \\
\hline $\begin{array}{l}\text { FOCO DE } \\
\text { PESQUISA }\end{array}$ & $\begin{array}{l}\text { Sistemas de } \\
\text { informação e } \\
\text { processos técnicos } \\
\text { e tecnológicos }\end{array}$ & $\begin{array}{l}\text { Usuários e seus } \\
\text { processos psicológicos } \\
\text { na apropriação da } \\
\text { informação }\end{array}$ & $\begin{array}{l}\text { Processos sociais, coletivos } \\
\text { e interacionista na } \\
\text { apropriação da informação }\end{array}$ \\
\hline $\begin{array}{l}\text { OBJETO } \\
\text { PRINCIPAL DA } \\
\text { PESQUISA } \\
\end{array}$ & $\begin{array}{l}\text { Informação (exclui } \\
\text { papel ativo do } \\
\text { sujeito) }\end{array}$ & Sujeito & Sujeito contextualizado \\
\hline $\begin{array}{l}\text { TIPOS DE ESTUDOS } \\
\text { DESENVOLVIDOS }\end{array}$ & $\begin{array}{l}\text { * Estudos de } \\
\text { usuário } \\
\text { quantitativo } \\
\text { * Tratamento da } \\
\text { informação busca } \\
\text { linguagem } \\
\text { universal e ideal } \\
\text { * Recuperação da } \\
\text { informação com } \\
\text { enfoque no } \\
\text { sistema }\end{array}$ & $\begin{array}{l}\text { * Estudo de usuário } \\
\text { qualitativo } \\
\text { * Tratamento da } \\
\text { informação para } \\
\text { usuário } \\
\text { * Recuperação da } \\
\text { informação com } \\
\text { enfoque no usuário }\end{array}$ & $\begin{array}{l}\text { * Estudo de usuário com } \\
\text { enfoque construtivista } \\
* \text { Tratamento da } \\
\text { informação admite } \\
\text { polissemia e reconhece que } \\
\text { cada comunidade possui } \\
\text { critérios próprios de } \\
\text { seleção da informação } \\
\text { * Relação entre tecnologia } \\
\text { e contexto social na } \\
\text { construção da informação } \\
\text { * Processo de mediação e } \\
\text { serviços de informação }\end{array}$ \\
\hline $\begin{array}{l}\text { CONCEITO DE } \\
\text { INFORMAÇÃO }\end{array}$ & $\begin{array}{l}\text { Baseado na ideia } \\
\text { de transferência e } \\
\text { transmissão da } \\
\text { informação }\end{array}$ & $\begin{array}{l}\text { Baseado na ideia de } \\
\text { transferência e } \\
\text { transmissão da } \\
\text { informação }\end{array}$ & $\begin{array}{l}\text { Baseado na ideia de } \\
\text { apropriação e construção } \\
\text { coletiva da informação }\end{array}$ \\
\hline
\end{tabular}

Fonte: Adaptado de Capurro [2009?] e Silva (2017).

Os três paradigmas da CI não devem ser considerados lineares e nem como substitutos um do outro, pois são cumulativos e associativos, com ramificações que complementam um ao outro. Cada paradigma foca sua pesquisa em um aspecto que envolve o processo de acesso, apropriação e disseminação da informação e, por consequência, fornece uma compreensão mais holística dos fatores envolvidos no processo.

Para finalizar a discussão sobre CI, é importante destacar que a área sempre esteve polarizada entre duas dimensões: a tecnológica e a social. No campo tecnológico, há uma 


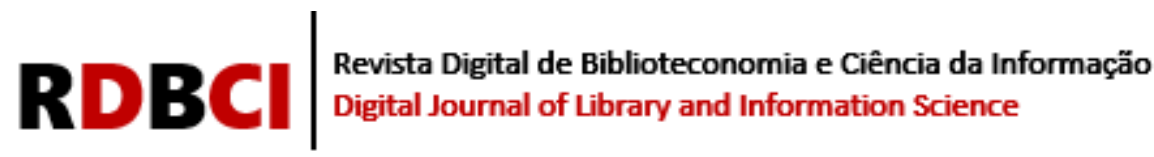

conexão inexorável entre a Ciência da Informação e a Tecnologia da Informação, sendo a intervenção mais visível a utilização de computadores na representação e recuperação da informação, além é claro da automatização de vários processos do fluxo de criação, armazenamento e uso da informação. No campo social, há a preocupação com o usuário, a forma como a tecnologia é utilizada, as necessidades informacionais individuais e institucionais e o fluxo da informação dentro de um contexto específico. Estas duas dimensões devem ser trabalhadas de forma integrada, pois a informação é processada tanto na existência humana quanto na existência dentro de uma máquina (GOFFMAN, 1970 apud PINHEIRO; LOUREIRO, 1995), e há uma constante interconexão entre os sistemas humanos e tecnológicos. Portanto, é necessário trabalhar não só com as novas tecnologias disponíveis, mas também com a capacidade de cognição humana ao se relacionar com os aparatos tecnológicos e considerar as especificidades do contexto onde o indivíduo está inserido.

\section{BIBLIOTECAS UNIVERSITÁRIAS: ENTRE O SOCIAL E O ESTRATÉGICO}

Segundo Tarapanoff (1999, p. 29), a sociedade do conhecimento é baseada em um modelo sócio-tecnológico, "onde a informação e o acesso à informação encontram-se presentes na vida social e econômica dos povos". Com o surgimento das tecnologias de comunicação e informação (TIC), o processo de criação e disseminação da informação foi agilizado e democratizado, facilitando o seu compartilhamento. O acesso à informação pelos indivíduos torna-se uma necessidade básica de sobrevivência tanto a nível pessoal e profissional como também para exercer sua cidadania. Nesse contexto, as bibliotecas possuem a importante missão de serem facilitadoras no acesso à informação.

No campo universitário, o domínio do sistema capitalista de produção, que demanda constante crescimento econômico, faz com que surjam novas exigências educacionais, pois requer mão-obra-obra mais qualificada. Com isso, as matrículas nas universidades crescem e as BUs tornam-se um instrumento auxiliar na qualificação da população tanto para atuar no mercado como na área de pesquisa acadêmica.

No Brasil, as bibliotecas universitárias são, geralmente, as mais bem equipadas e as que recebem mais investimentos. Devido às avaliações periódicas realizadas pelo MEC (Ministério de Educação), que atrela a qualidade do acervo e serviços prestados às notas dos cursos ofertados pelas universidades, há um interesse institucional em promover seu desenvolvimento, além é claro de ser um suporte para a comunidade acadêmica onde está inserida.

Devido a essa posição "privilegiada", as bibliotecas universitárias brasileiras em muitas situações se veem na função de assumir responsabilidades não atendidas por outros tipos de biblioteca. Por exemplo, alunos recém-chegados à universidade podem possuir pouca ou nenhuma competência informacional ${ }^{1}$, algo que deveria ter desenvolvido desde a fase escolar. Dada a precariedade de muitas bibliotecas públicas brasileiras, as BUs em algumas cidades também assumem a função de democratizar o acesso à informação, oferecendo alguns serviços, como consulta local e acesso à internet, para o público não acadêmico.

As bibliotecas acadêmicas, portanto, representam um campo de atuação que absorve tanto os preceitos educacionais e democráticos da Biblioteconomia contemporânea como

1 Competência informacional, segundo Dudziak (2003, p.28) é definida como "processo contínuo de internalização de fundamentos conceituais, atitudinais e de habilidades necessário à compreensão e interação permanente com o universo informacional e a sua dinâmica, de modo a proporcionar um aprendizado ao longo da vida." 


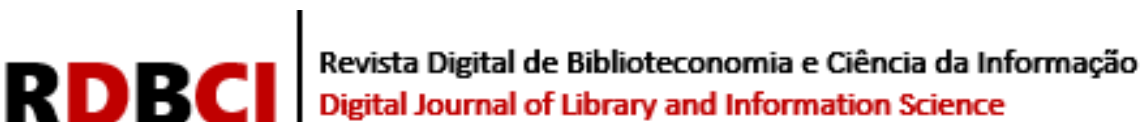

também os preceitos estratégicos e de competividade da Ciência da Informação. Ou seja, as BUs têm um papel tanto educativo, ao capacitar o usuário para acessar fontes de informação confiáveis e desenvolver estratégias de busca, como também deve fornecer acesso a informações que auxiliem os usuários não só a obter sucesso acadêmico ao longo do curso como também formar profissionais com uma carga de conhecimento adequado para desenvolver suas atividades profissionais (OLIVEIRA; CRANCHI, 2017). Portanto as BUs auxiliam tanto a desenvolver o indivíduo enquanto pessoa autônoma e crítica como também enquanto mão-deobra ou "recurso" humano para organizações.

Contudo, as bibliotecas universitárias e a própria universidade como um todo enfrentam uma crise atualmente. Na nova era da pós-modernidade ou modernidade líquida, como é definida pelo sociólogo Bauman (2001), as transformações são constantes e muito rápidas. Em um cenário tão dinâmico e instável, as universidades muitas vezes possuem uma atuação muito lenta e acabam por ensinar conhecimentos que serão obsoletos quando os estudantes chegarem ao final de sua formação e as BUs também demonstram não serem capazes de oferecer soluções informacionais que auxiliem seus usuários a lidar com essa nova realidade. As instituições de ensino formal se veem então numa encruzilhada, pois passam a disputar espaço com novas e alternativas opções de acesso ao conhecimento (TEDESCO, 2006). Se antes, as escolas e universidades eram locais exclusivos para o processo de ensinoaprendizagem, atualmente é possível encontrar "professores" em outros lugares, como, por exemplo, em canais de Youtube, blogs de discussão e mídias sociais. Normalmente, essas novas opções são interativas (não é uma comunicação unilateral, pois tem recursos para comentários e interação entre os indivíduos), de fácil acesso (não é preciso deslocar-se para acessar o conteúdo) e com custo pouco elevado (muitas plataformas são, inclusive, gratuitas).

Em uma sociedade na qual a grande maioria dos indivíduos prefere procurar informação na internet ao invés de buscar livros e serviços tradicionais, o papel das bibliotecas passa ser intensamente questionado, com o seu fim sendo até mesmo apregoado por alguns. Apesar das justificativas, pertinentes, de que os serviços da biblioteca oferecem um tipo de organização, credibilidade e confiabilidade que não podem ser encontrados em muitas fontes de informação on-line, ainda assim as bibliotecas necessitam atualizar os serviços e produtos oferecidos e promover inovações para atender com mais eficiência e destreza as novas demandas do usuário, que procura um serviço de informação ágil, fácil de utilizar, personalizado e, de preferência, que seja disponibilizado de forma remota por meio de dispositivos móveis.

Algumas inovações têm sido implementadas, embora ainda tímidas. Nas primeiras tentativas de inovação dentro das bibliotecas, o foco maior era na parte tecnológica, mas atualmente há uma preocupação bem maior com o lado humanístico da questão. A tecnologia deixa de ser um fim em si mesmo para ser um meio para alcançar objetivos institucionais e individuais da sociedade e indivíduos. Para Davenport (1998, p. 11-12),

\footnotetext{
Nosso fascínio pela tecnologia nos fez esquecer o objetivo principal da informação: informar. Todos os computadores do mundo de nada servirão se seus usuários não estiverem interessados na informação que esses computadores podem gerar. $\mathrm{O}$ aumento da largura de banda dos equipamentos de telecomunicações será inútil se os funcionários de uma empresa não compartilharem a informação que possuem. [...] A abordagem comumente aceita para o gerenciamento de informações investimento em novas tecnologias, e só — simplesmente não funciona.
}

Por isso, mais do que simplesmente preocupar-se com a disponibilização de novos recursos tecnológicos, a unidade de informação deve ter uma visão holística do processo de busca, acesso e utilização da informação, sempre focando nas necessidades dos usuários. A falha em considerar a questão humana na disponibilização da informação pode levar à alienação 


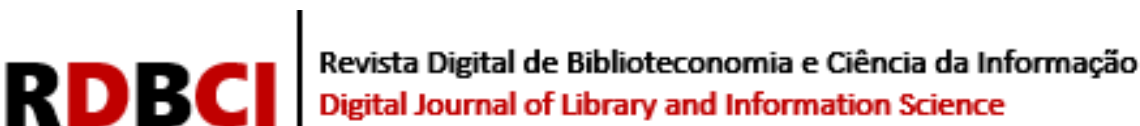

do usuário, que não terá suas necessidades atendidas adequadamente e irá procurar outros locais, físicos ou virtuais, que lhes sejam mais uteis.

Do ponto de vista da gestão de unidades de informações, ao se constatar a perda desses "clientes", torna-se imperativo investigar o que está provocando este afastamento dos usuários e quais as melhores estratégias para alcançá-los novamente. Pois, embora as BUs ainda tenham a força das avaliações do MEC a seu favor, o objetivo final das bibliotecas deve ser primariamente atender seu público da forma mais acurada possível. Na criação das estratégias de reconquista do público atendido os gestores das bibliotecas precisam entender como ocorre o fluxo de informação dentro do campo cientifico e acadêmico, como os usuários dessa comunidade se comportam, quais ferramentas tecnológicas e fontes de informação formais e informacionais estão disponíveis, quais tendências irão permanecer e quais são apenas modismos passageiros. $\mathrm{O}$ foco das bibliotecas deve estar também em capacitar o usuário a lidar com o enorme volume de informação, a saber reconhecer a confiabilidade e qualidade da informação recebida, e como se atualizar profissionalmente em uma sociedade em constante movimento.

As BUs, por serem o tipo de biblioteca que mais recebe investimentos no Brasil, devem assumir também um papel de responsabilidade social e auxiliar os estudantes que possuem mais dificuldade no processo de ensino-aprendizagem. Esses discentes muitas vezes abandonam a universidade por não terem o suporte necessário para melhorar suas técnicas de estudo e aprendizagem ou se formam sem adquirir o conhecimento necessário para serem profissionais bem qualificados no mercado de trabalho. A evasão ou baixa aprendizagem desses estudantes implica em perda para o indivíduo pessoalmente, para a universidade que empregou recursos em algo que não foi concluído e para o mercado de trabalho que sofre muitas vezes para conseguir mão-de-obra qualificada. Considerando as origens elitistas das universidades, as BUs podem contribuir para com a construção de uma história mais democrática do ensino superior e de uma sociedade mais justa. Pois, embora verifique-se a implementação de ações governamentais brasileiras que visam a diminuição de desigualdades de acesso e permanência em instituições públicas de ensino superior, ainda há parcelas da comunidade universitária que continuam a enfrentar grandes dificuldades para manter seu estudo.

Ao realizar o planejamento das ações de aprimoramento dos produtos, serviços e procedimentos das bibliotecas universitárias, os gestores das BUs podem adotar as mesmas perspectivas dos paradigmas da Ciência da Informação: foco na melhoria dos sistemas e técnicas empregados (paradigma físico); foco no usuário de uma forma mais personalizada e individual (paradigma cognitivo); foco nos sistemas de informações externos à biblioteca e nos novos comportamentos informacionais dos usuários (paradigma social). Ao se fazer um planejamento que considere os três aspectos citados, as bibliotecas universitárias poderão ser mais eficazes no desempenho de suas funções e oferecer um serviço diferenciado e sistêmico para seu público.

Para alcançar as alterações propostas, o gestor também terá de ser um líder capaz de envolver os seus comandados, motivá-los e orientá-los para desempenhar novas funções. Essa questão é de extrema importância, pois o profissional bibliotecário, normalmente, possui um perfil mais técnico e a Biblioteconomia é um campo do conhecimento com uma tendência a uma certa estagnação. Para fazer frente aos novos desafios e oportunidades enfrentados pelas bibliotecas, uma tendência atualmente discutida é a de embedded librarianship, ou Biblioteconomia integrada, que

\footnotetext{
é uma inovação diferenciada que move os bibliotecários para fora das bibliotecas e cria um novo modelo de biblioteca e trabalho com informação. Esse conceito enfatiza a importância de formar uma relação de trabalho forte entre o bibliotecário e um grupo ou equipe de pessoas que precisam do conhecimento em informação do
} 


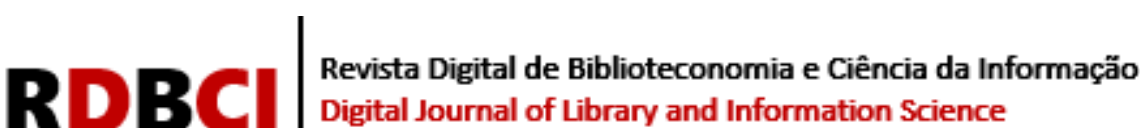

\begin{abstract}
bibliotecário. À medida que o relacionamento se desenvolve, o conhecimento e a compreensão do bibliotecário sobre o trabalho e os objetivos do grupo aumentam, o que leva, por sua vez, a um maior discernimento sobre as necessidades de informação e conhecimento do grupo. O bibliotecário integrado torna-se tão envolvido no trabalho da equipe quanto qualquer outro membro do time. À medida que o engajamento cresce, o bibliotecário integrado desenvolve contribuições altamente personalizadas, sofisticadas e de valor agregado para a equipe contribuições que às vezes vão muito além dos limites do trabalho de referência tradicional da biblioteca e que podem surpreender alguns ao constatar a atuação de um bibliotecário como responsável pela tarefa. O bibliotecário funciona como um membro da equipe como qualquer outro - e compartilha a responsabilidade pelos resultados da equipe e da organização com todos os outros membros da equipe. (SHUMAKER, 2012, p. 4, tradução livre).
\end{abstract}

A definição acima é bem próxima do que seria um cientista da informação nos primórdios do desenvolvimento da área de Ciência da Informação. De acordo com Araújo (2014b), nas décadas de 1920 a 1940, especialmente na Inglaterra e nos Estados Unidos, cientistas começaram a desempenhar atividades para disseminação entre seus demais colegas de informações sobre suas respectivas áreas de atuação. Eram químicos, físicos, engenheiros e outros cientistas que começaram a elaborar índices, resumos e difundir canais de comunicação para auxiliar no trabalho de seus pares. A Biblioteconomia integrada propõe um caminho inverso, onde, ao invés do cientista realizar tarefas de organização e difusão da informação, o bibliotecário levará sua expertise para atuar de forma mais imersiva na realidade dos usuários a serem atendidos.

Dessa forma, depreende-se que o bibliotecário universitário precisa deixar de ser um ator coadjuvante no processo de ensino-aprendizagem dentro das universidades e assumir um papel mais atuante perante os usuários, sejam eles discentes ou docentes. O suporte prestado pelas bibliotecas universitárias deve ser perceptível perante a comunidade acadêmica atendida, que contará com o profissional bibliotecário como um aliado importante na busca por informação e conhecimento. Para isso as bibliotecas devem ser visionárias, com capacidade de fazer antecipação de demandas e incorporar rapidamente as novas tecnologias da informação e comunicação que surgirem, gerando serviços personalizados, eficientes e de qualidade. A parte mais técnica da biblioteca ainda continuará a ser demanda, mas com a informatização as atividades educativas e de curadoria de informação especializada será o que manterá as bibliotecas universitárias como instituições relevantes.

\section{CONSIDERAÇÕES FINAIS}

As bibliotecas universitárias estão sendo imensamente impactadas pelas mudanças tecnológicas e de comportamento informacional dos usuários. Devido ao processo de ensinoaprendizagem estar mais flexível e disperso em inúmeros recursos e fontes de informação, o público atendido precisa de uma biblioteca mais inovadora e dinâmica para atender suas necessidades de informação. Com usuários mais habilidosos na utilização das tecnologias da informação e comunicação, é responsabilidade das bibliotecas universitárias adaptarem seus serviços e produtos para suprir as novas demandas. Este é um tema complexo, que requer atualização profissional constante por parte dos bibliotecários e também dos cursos de Biblioteconomia, que devem formar profissionais capacitados para lidar com as constantes alterações nos fluxos informacionais da sociedade contemporânea.

Nesse contexto de profundas e rápidas transformações, as bibliotecas estão lentamente alterando alguns de seus preceitos/paradigmas. O principal é a substituição da ideia de posse da 


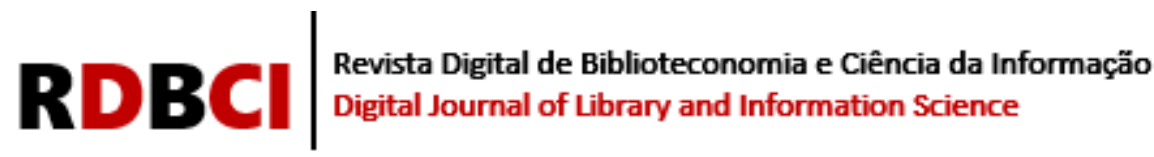

informação pela de acesso à informação. Ou seja, mais do que acumular obras impressas na biblioteca, os profissionais da área devem dar acesso à informação, seja através da assinatura de bases de dados ou através de convênios com outras bibliotecas e instituições. Outra mudança é que se antes, no início da democratização do acesso à educação, havia o incentivo à leitura, atualmente é preciso também formar usuários que sejam independentes e autônomos na procura de informação e criação do conhecimento, transformando-os em indivíduos capacitados para encontrar a informação necessária em qualquer fonte por conta própria.

É importante lembrar que a Ciência da Informação é tanto uma ciência pura, na medida que investiga o objeto informação de forma isolada, como também uma ciência aplicada, visto que é voltada a criação de serviços e produtos (BORKO, 1968). Apropriando-se dessas características, as bibliotecas universitárias, que já estão inseridas em um ambiente propício a pesquisa, devem ser menos reativas às mudanças ocorridas na sociedade e começar a trabalhar com uma atuação de vanguarda e com uma visão visionária para se antecipar às necessidades informacionais de seus usuários, sempre buscando atrelar os serviços à qualificação de profissionais com habilidade para impactarem posteriormente o campo de trabalho onde irão atuar, seja ele na esfera pública ou privada.

Do campo da Biblioteconomia, as bibliotecas universitárias devem buscar aperfeiçoar as técnicas e procedimentos consagrados da área e não esquecer dos aspectos mais humanistas que a permeiam. É preciso reconhecer as dicotomias entre tecnologia/técnica x social, interesses públicos x privados, interesses individuais x organizacionais, e tentar superar essas dualidades. As bibliotecas universitárias, e a universidade como um todo, devem procurar integrar todos os interesses e criar soluções mais robustas para resolver os desafios informacionais da sociedade atual e gerar valor para os usuários e para sociedade.

\section{REFERÊNCIAS}

ARAÚJO, Carlos Alberto Ávila. A ciência da informação como ciência social. Ciência da Informação, Brasília, DF, v. 32, n. 3, p. 21-27, set./dez. 2003. Disponível em: http://www.scielo.br/pdf/ci/v32n3/19020.pdf. Acesso em: 26 fev. 2020.

ARAÚJO, Carlos Alberto Ávila. Arquivologia, Biblioteconomia, Museologia e Ciência da Informação. São Paulo: Briquet de Lemos, 2014a.

ARAÚJO, Carlos Alberto Ávila. Ciência da informação, Biblioteconomia, Arquivologia e Museologia: relações institucionais e teóricas. Encontros Bibli, Florianópolis, SC, v. 16, n. 31, p.110-130, 2011. Disponível em:

https://periodicos.ufsc.br/index.php/eb/article/view/15182924.2011v16n31p110. Acesso em: 6 maio 2020.

ARAÚJO, Carlos Alberto Ávila. O que é a Ciência da Informação. Informação \& Informação, Londrina, v. 19, n. 1, p. 1-30, jan./abr. 2014b. Disponível em: http://www.uel.br/revistas/uel/index.php/informacao/article/viewFile/15958/14205. Acesso em: 06 maio 2020.

BAUMAN, Zygmunt. Modernidade líquida. Rio de Janeiro: J. Zahar, 2001. 


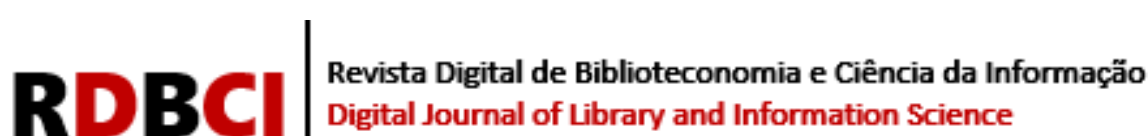

BORKO, Harold. Ciência da Informação: o que é isso? 1968. (Tradução livre). Disponível em: https://edisciplinas.usp.br/pluginfile.php/3433774/mod_resource/content/1/ Oque\%C3\%A9CI.pdf. Acesso em: 26 fev. 2020.

CAPURRO, Rafael. Epistemologia e Ciência da Informação. [2009?]. Disponível em: http://www.capurro.de/enancib_p.htm. Acesso em: 26 fev. 2020.

CARDOSO, Ana Maria Cardoso. Pós-modernidade e informação: conceitos complementares? Perspectivas em Ciência da Informação, Belo Horizonte, v. 1, n. 1, p. 63-79, jan./jun.1996. Disponível em: https://www.brapci.inf.br/_repositorio/2010/08/pdf_44afe65e85_0011622.pdf. Acesso em: 26 fev. 2020.

DIAS, Eduardo José Wense. Biblioteconomia e Ciência da Informação: natureza e relações. Perspectivas em Ciência da Informação, Belo Horizonte, v. 5, n. especial., p. 67-80, jan./jun. 2000. Disponível em: portaldeperiodicos.eci.ufmg.br/index.php/pci/article/download/ 556/338. Acesso em: 26 fev. 2020.

DUDZIAK, Elizabeth Adriana. Information literacy: princípios, filosofia e prática. Ciência da Informação, Brasília, v. 32, n. 1, p. 23-35, /abr, 2003. Disponível em: https://www.scielo.br/scielo.php?pid=S010019652003000100003\&script=sci_abstract\&tlng=pt. Acesso em: 6 maio 2020.

FONSECA, Edson Nery da. Introdução a biblioteconomia. 2. ed. Brasília, DF: Briquet de Lemos, 2007.

LE COADIC, Yves-François. A ciência da informação. 2.ed. Brasília, DF: Briquet de Lemos, 2004.

MARTELETO, Regina Maria. A pesquisa em Ciência da Informação no Brasil: marcos institucionais, cenários e perspectivas. Perspectivas em Ciência da Informação, Belo Horizonte, v. 14, número especial, p. 19-40, 2009. Disponível em:

http://www.scielo.br/pdf/pci/v14nspe/a03v14nspe.pdf. Acesso em: 26 fev. 2020.

MARTINS, Wilson. A palavra escrita: história do livro, da imprensa e da biblioteca. 3. ed. rev. atual. São Paulo: Ática, 1998.

OLIVEIRA, Antonio José Barbosa de; CRANCHI, Daniela Carvalho. O papel da biblioteca universitária como espaço de afiliação estudantil e o bibliotecário como educador e agente inclusivo. Informação e Sociedade, João Pessoa, v. 27, n.2, maio/ago. 2017. Disponível em: https://www.brapci.inf.br/_repositorio/2017/09/pdf_19b32a6dcd_0000026879.pdf. Acesso em 06 maio 2020.

ORTEGA, Cristina Dotta. Relações históricas entre Biblioteconomia, Documentação e Ciência da Informação. DataGramaZero - Revista de Ciência da Informação, João Pessoa, v. 5, n. 5, out. 2004. Disponível em:

http://www.brapci.inf.br/index.php/article/view/0000002048/ e908b9a74b0fb8f5aff3bd1881eec6b2/. Acesso em: 26 fev. 2020. 


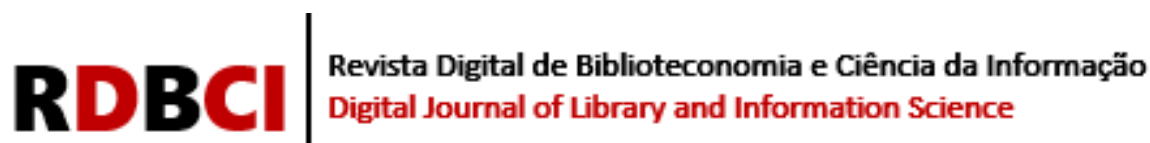

PINHEIRO, Lena Vania Ribeiro; LOUREIRO, José Mauro Matheus. Traçados e limites da ciência da informação. Ciência da Informação, Brasília, DF, v. 24, n. 1, p. 52-61, maio/ago. 1995. Disponível em: http://revista.ibict.br/ciinf/article/view/609/611. Acesso em: 26 fev. 2020.

SILVA, Jonathas Luiz Carvalho. Fundamentos da informação I: perspectivas em ciência da informação. São Paulo: ABECIN, 2017. 263p. Disponível em:

http://www.repositoriobib.ufc.br/000042/00004231.pdf. Acesso em: 26 fev. 2020.

SHUMAKER, David. The embedded librarian: innovative strategies for taking knowledge where its needed. Medford: Information Today, 2012.

TARAPANOFF, Kira Maria Antonia. O profissional da informação e a sociedade do conhecimento: desafios e oportunidades. Transinformação, Campinas, v. 11, n. 1, p. 27-38, 1999. Disponível em: http://www.brapci.inf.br/index.php/article/download/14966. Acesso em: 26 fev. 2020.

TEDESCO, Juan Carlos. Educar na sociedade do conhecimento. Araraquara: Junqueira e Marin, 2006. 